\title{
Second branchial cleft anomaly
}

INSERM

\section{Source}

INSERM. (1999). Orphanet: an online rare disease and orphan drug data base. Second branchial cleft anomaly. ORPHA:141022

A rare otorhinolaryngological malformation characterized by the presence of a cyst, sinus or fistula occuring along the anterior border of the sternocleidomastoid muscle. Second branchial cleft fistulae ans sinuses present with skin opening with chronic discharge and recurrent infections, whereas second branchial cleft cysts present as a painless, nontender, stable in size or slowly enlarging lateral neck masses. Cysts occasionally acutely increase in size during upper respiratory tract infection, leading to respiratory compromise, torticollis, and dysphagia. 